Check for updates

Cite this: RSC Adv., 2019, 9, 19539

Received 9th April 2019

Accepted 16th June 2019

DOI: 10.1039/c9ra02671a

rsc.li/rsc-advances

\section{New ecological method for determination of different $\beta$-lactams: application to real human plasma samples}

\begin{abstract}
Nehal F. Farid (D) a and Nada S. Abdelwahab (D)*ab
Recently, the use of antibiotics has become widespread all over the world resulting in bacterial resistance to these antibiotics, which requires alternative medications or higher doses of antibiotics. Implementation of an easy analytical method that can analyze a wide range of $\beta$-lactam antibiotics in a single run is important to reduce the time of therapeutic drug monitoring (TDM) in hospitals and minimize the spreading of bacterial resistance. A novel environmentally harmless HPTLC method was developed and validated following FDA recommendations for analysis of four $\beta$-lactams; cefaclor, cefotaxime, cefepime, and meropenem, in human plasma. A solvent mixture of ethylacetate : methanol : deionized water : formic acid (60:30:15:1, by volume) was the used developing system, detection was carried out at $270 \mathrm{~nm}$, and valacyclovir was used as an internal standard. A lower limit of quantitation (LLOQ) was found to be $0.1 \mu \mathrm{g}$ per band for all the analyzed drugs. Validation parameters were calculated and found to fulfil the international requirements for bio-analytical method validation. Additionally, each of the studied antibiotics was given to a group of healthy volunteers from which blood samples were collected at $t_{\max }$ of each, methanol was used for precipitation of plasma protein, and the developed method was used for calculation of the concentrations in the separated plasma samples. The developed method, being a green one, and time and money saving, can be used for TDM of these drugs in clinical studies as well as for quality control analysis in pharmaceutical companies. The proposed method is the first developed HPTLC method for the simultaneous bio-analysis of the selected $\beta$-lactams.
\end{abstract}

\section{Introduction}

$\beta$-Lactam antibiotics are the most commercially used antibiotics in the world, they work by inhibiting cell wall biosynthesis in bacteria. ${ }^{1}$ Cephalosporins and carbapenems are two classes of $\beta$-lactam antibiotics that are prescribed for serious infections that involve a wide bacterial range. The drugs under study include cephalosporins [cefaclor $\left(2^{\text {nd }}\right.$ generation $)$, cefotaxime $\left(3^{\text {rd }}\right.$ generation $)$ and cefepime $\left(4^{\text {th }}\right.$ generation $\left.)\right]$, and meropenem which is an example of carbapenems.

Cephalosporins are broad-spectrum antibacterial drugs; they are the second largest class of $\beta$-lactam antibiotics with excellent safety profiles. Third and fourth generations are able to penetrate the blood-brain barrier and reach the central nervous system with sufficient concentrations; thus they are effective in the treatment of meningitis. On the other hand, carbapenems have the broadest spectrum activity and greatest potency against Gram negative and Gram positive bacteria, hence they are used as last resort antibiotics for resistant bacteria, ${ }^{2}$ so they are considered lifesaving drugs. ${ }^{3}$

aPharmaceutical Analytical Chemistry, Faculty of Pharmacy, Beni-Suef University, Beni-Suef, Egypt. E-mail: nadasayed2003@yahoo.com; nehalfayek@gmail.com; Tel: +20 1285999726; +20 1277950994

${ }^{b}$ Pharmaceutical Chemistry, Faculty of Pharmacy, Nahda University (NUB), Beni-Suef, Egypt
Appraising the literature, different methods were published for analysis of $\beta$-lactam antibiotics in different biological fluids (cefotaxime and cefepime reviews were reported by Consortti and Salgado ${ }^{4}$ and Omkulthom ${ }^{5}$ ). The published methods for $\beta$ lactam antibiotics include HPLC, ${ }^{6-15}$ LC-MS-MS, ${ }^{16-23}$ and capillary electrophoresis. ${ }^{24-28}$ Few TLC densitometric methods were found for analysis of different pharmaceutical formulations containing $\beta$-lactam antibiotics. ${ }^{29-34}$ Only one TLC densitometric method was published for in vitro determination of cefepime. ${ }^{35}$ Based on the literature survey, no HPTLC method was found in the literature for the in vivo determination of the studied $\beta$-lactam antibiotics.

Planar chromatography has wide applications ranging from simple screening tests to complicated instrumental quantitative analysis of different samples in different matrices. TLC is one of planar chromatographic methods which has the advantages of time and money saving. ${ }^{36,37}$ It has extensive applications in pharmaceutical analysis, ${ }^{38,39}$ identification of impurities, ${ }^{40,41}$ isolation and separation of biomedical metabolites or constituents from different body fluids with minimum sample pretreatment. ${ }^{42,43}$ It is also used for separation of identical compounds in a mixture. ${ }^{36,37}$ Recently, HPTLC is an improved form of TLC with better resolution and more accurate quantitative measurements. Complex mixtures can be visualized on HPTLC chromatograms at a glance. ${ }^{37}$ 
One of the significant problems all over the world is the environmental pollution due to the wide use of hazardous chemicals and solvents. The concept of green chemistry developed as natural evolution of pollution prevention. From the goals of green chemistry is to use alternatives to hazardous substances and to develop new analytical methods that can reduce waste and toxic solvents. ${ }^{\mathbf{4}}$

Paying attention to environmental issues and the importance of $\beta$-lactam antibiotics, the novelty of this work is to develop and validate an ecological HPTLC method to monitor the studied $\beta$-lactam antibiotics in human plasma and to ensure a safe and effective treatment for patients, hence, decrease the extensive use of these antibiotics and minimize their bacterial resistance. Furthermore, the method was validated according to FDA guidelines ${ }^{45}$ and all results agreed with the acceptance limits. The most striking features of the proposed method are its simplicity and short analysis time. Furthermore, it is the first HPTLC method for quantitation of the cited drugs in human plasma with minimal sample pretreatment.

\section{Materials and methods}

\section{Instruments}

For preparation of plasma samples. Rongtai variable volume micropipette (0.1-100 $\mu \mathrm{L}$ ) (Mainland, Shanghai, China) was used for taking samples accurately, while for mixing samples 250 VM vortex mixer (Hwashin, Seoul, Korea) was used. Centrifugation and separation of the precipitated plasma protein was carried out by using 80-2C Low-speed Electric Centrifuge $(4000 \mathrm{rpm})(12$ tube $\times 20 \mathrm{~mL})($ Zjmzym, China) was used.

For HPTLC method. The used stationary phase was HPTLC aluminum plates $(20 \times 15 \mathrm{~cm})$ pre-coated with silica gel $60 \mathrm{~F}_{254}$ with $200 \mu \mathrm{m}$ thickness and $5 \mu \mathrm{m}$ particle size (Merck, Darmstadt, Germany). Samples was applied as bands using a Linomat V applicator with $100 \mu \mathrm{L}$ syringe. Scanning was done by TLC scanner, model $3 \mathrm{~S} / \mathrm{N}$ (Camag, Muttenz, Switzerland) controlled with winCATS software (version 3.15).

Optimization of the method was carried out using a short wavelength, $254 \mathrm{~nm}$ UV lamp (Vilber Lourmat, Marne La Vallee, Cedex, France).

\section{Standards and reagents}

- Cefaclor was provided by Pharco (Alexandria, Egypt), Alex for Chemical Industries \& Drugs (Alexandria, Egypt) and certified to have a purity of $98.98 \%$.

- Cefotaxime sodium was supplied from Egyptian International Pharmaceutical Industries Co. (E.I.P.I.Co.), $10^{\text {th }}$ of Ramadan City, Industrial Area, Egypt, with a purity of $99.02 \%$ according to the manufacturer certificate of analysis.

- Cefepime hydrochloride, with a purity of $98.95 \%$, was given as a gift by Pharco B International, New Borg El Arab City, Third Industrial Zone, Alexandria, Egypt.

- Meropenem was purchased from (Sigma-Aldrich Chemie $\mathrm{GmbH}$, Germany), with a purity of $98.89 \%$ purity.
- Valacyclovir with purity of $99.21 \%$ according to the supplier certificate of analysis and was provided by Hikma Pharma $\left(6^{\text {th }}\right.$ of October City, Egypt).

- Ethylacetate, methanol, formic acid (EL-Nasr pharmaceutical, Chemical Co., Abu Zabaal, Cairo, Egypt).

- Deionized water (SEDICO Pharmaceuticals Co., $6^{\text {th }}$ October City, Egypt).

\section{Pharmaceutical formulations}

- Bacticlor ${ }^{\circledR}$ (0.5 g cefaclor per capsule), manufactured by Pharco (Alexandria, Egypt), Alex for Chemical Industries \& Drugs (Alexandria, Egypt).

- Cefotax ${ }^{\circledR}(1 \mathrm{~g}$ for I.M. or I.V. injection), is labeled to contain $1048 \mathrm{mg}$ cefotaxime sodium (equivalent to $1000 \mathrm{mg}$ cefotaxime), and is manufactured by Egyptian International Pharmaceutical Industries Co. (E.I.P.I.Co.), 10th of Ramadan City, Industrial Area, Egypt.

- Forcetex® (1 g for I.M. or I.V. injection), containing $1213 \mathrm{mg}$ cefepime hydrochloride (corresponding to $1000 \mathrm{mg}$ cefepime) and is manufactured by Pharco B International, New Borg El Arab City, Third Industrial Zone, Alexandria, Egypt for Novartis Pharma. Cairo, Egypt.

- Meronem ${ }^{\circledR}$ ( $0.5 \mathrm{~g}$ for I.V. injection) is manufactured by ACS Dobfar SpA, Italy for AstraZeneca UK Limited, Macclesfield, Cheshire, SK 102 NA, United Kingdom.

\section{Blank plasma samples}

- Blank plasma samples were provided by Dr Khaled Nagy Laboratory, Beni-Suef, Egypt and they were collected from healthy voluntary donors to be used as a blank matrix.

\section{Chromatographic conditions}

The used stationary phase was HPTLC aluminum plates $(20 \times$ $15 \mathrm{~cm}$ ) pre-coated with silica gel $60 \mathrm{~F}_{254}$ with $200 \mu \mathrm{m}$ thickness and $5 \mu \mathrm{m}$ particle size (Merck, Darmstadt, Germany) and the mobile phase was consisted of a solvent mixture of ethylacetate : methanol : deionized water : formic acid (60:30:15:1, by volume). Samples was applied using Camag Linomat $\mathrm{V}$ applicator as bands of $4 \mathrm{~mm}$ width, $5 \mathrm{~mm}$ apart from each other, and $15 \mathrm{~mm}$ from the bottom edge of the plate. Chromatographic development was done in a glass jar saturated with the mobile phase mixture for $15 \mathrm{~min}$. The temperature was maintained constant at $25{ }^{\circ} \mathrm{C}$ and UV scanning was carried out at $270 \mathrm{~nm}$ for all the studied drugs.

\section{Solutions}

Cefaclor, cefotaxime, cefepime, meropenem, and valacyclovir (IS) stock solutions $\left(1 \mathrm{mg} \mathrm{mL}^{-1}\right)$ were separately prepared in methanol using five separate $25 \mathrm{~mL}$ measuring flasks.

\section{Calibration curves}

For pure standards. Calibration curves were constructed in the concentration range of $0.06-3 \mu \mathrm{g}$ per band for the studied antibiotics. Different pure samples of each antibiotic in the range of $60-300 \mu \mathrm{g} \mathrm{mL} \mathrm{m}^{-1}$ were separately prepared in a set of 
$10 \mathrm{~mL}$ calibrated flasks using the corresponding stock solution $\left(1 \mathrm{mg} \mathrm{mL}{ }^{-1}\right) .1 \mathrm{~mL}$ of valacyclovir (IS) stock solution $(1 \mathrm{mg}$ $\mathrm{mL}^{-1}$ ) was accurately added to each sample and the volume was completed with methanol. $10 \mu \mathrm{L}$ of each sample was applied in duplicates to HPTLC plates and the steps mentioned under chromatographic conditions were then followed. The integrated peak area ratio (integrated peak area of the analyte/peak area of IS) was calculated and used to construct the calibration curves and computing the corresponding regression equations.

In vitro calibration standards and quality control (QC) samples. In vitro calibration curves were constructed in the range of $0.1-3 \mu \mathrm{g}$ per band. Various concentrations each of the studied components in the range of $100-300 \mu \mathrm{g} \mathrm{mL} L^{-1}$ were prepared from their particular stock solutions $\left(1 \mathrm{mg} \mathrm{mL}^{-1}\right)$ into four sets of $10 \mathrm{~mL}$ volumetric flasks. One $\mathrm{mL}$ each of drug free plasma and IS stock solution $\left(1 \mathrm{mg} \mathrm{mL}{ }^{-1}\right)$ were separately added to each sample, and then the volume was adjusted with methanol. The prepared samples were vortexed for one min and the precipitated plasma protein was then removed by centrifugation at $4000 \mathrm{rpm}$ for $5 \mathrm{~min} .10 \mu \mathrm{L}$ of the clear supernatant of each sample was then applied in duplicates to HPTLC plates following the instructions previously given under chromatographic conditions. Quality control samples were prepared in the same manner as calibration standards with concentrations of $0.6 \mu \mathrm{g}$ per band (LQC), $1.5 \mu \mathrm{g}$ per band (MQC), and $2.5 \mu \mathrm{g}$ per band (HQC). Calibration standard samples were freshly prepared at the time of analysis while QC samples were kept at $-20{ }^{\circ} \mathrm{C}$ during method validation period.

\section{Administration of the studied drugs and collection of plasma samples}

Blood samples were collected from healthy volunteers (informed on the experimental procedures, the nature of the study, and gave a written approval). Volunteers were divided into four groups $(n=6)$, group I, received a dose of $0.5 \mathrm{~g}$ Bacticlor ${ }^{\circledR}$ capsules, group II, took $1 \mathrm{~g}$ I.V. dose of Cefotax ${ }^{\circledR}$ injection, group III was injected I.V. with $1 \mathrm{~g}$ Forcetex ${ }^{\circledR}$ injection, and finally, group IV was injected I. V. with $0.5 \mathrm{~g}$ Meronem ${ }^{\circledR}$ injection. The age of the volunteers ranged from 20 to 45 years old with a weight range $50-75 \mathrm{~kg}$. Blood samples of $5 \mathrm{~mL}$ were collected at the specified time of each drug $\left(t_{\max }\right)$ $\left(t_{\max }\right.$ of cefaclor $=50 \mathrm{~min}$., cefotaxime $=2-5 \mathrm{~min}$., cefepime $=$ $30 \mathrm{~min}$., and meropenem $=5-6 \mathrm{~min}^{\mathbf{4 6 - 4 9}}$ ) in heparinized tubes and centrifuged at $4000 \mathrm{rpm}$ immediately after receipt. The separated plasma samples were stored at $-20{ }^{\circ} \mathrm{C}$ till the time of analysis.

\section{Preparation of the collected plasma samples}

Previously collected plasma samples were thawed to room temperature just before the extraction and the preparation procedures.

For cefaclor collected samples. In $5 \mathrm{~mL}$ centrifuge tubes, $1 \mathrm{~mL}$ of each sample was accurately transferred, then $40 \mu \mathrm{L}$ of IS stock solution ( $1 \mathrm{mg} \mathrm{mL}^{-1}$ ) was added, and the volume was adjusted to $2 \mathrm{~mL}$ with methanol. Samples were mixed well for one min and then centrifuged for $5 \mathrm{~min}$ at $4000 \mathrm{rpm} .50 \mu \mathrm{L}$ of the clear supernatant was then applied in triplicates to HPTLC plates.

For cefotaxime, cefepime, and meropenem collected samples. In three sets of $5 \mathrm{~mL}$ centrifuge tubes, $1 \mathrm{~mL}$ of each sample was accurately transferred to which $100 \mu \mathrm{L}$ of IS stock solution ( $1 \mathrm{mg} \mathrm{mL}^{-1}$ ) was added. The volume was then completed to $2 \mathrm{~mL}$ with methanol. Samples were vortexed for one min and then plasma protein was separated by centrifugation for $5 \mathrm{~min}$ at $4000 \mathrm{rpm} .20 \mu \mathrm{L}$ of the clear supernatant from each sample was then applied in triplicates to HPTLC plates.

Chromatographic development was then done following the instructions under chromatographic conditions. The peak area ratio was then calculated and used to calculate the concentrations of each drug in the collected plasma samples using the previously computed regression equations.

\section{Results and discussion}

Therapeutic drug monitoring of antibiotics is essential to diminish the spreading of bacterial resistance, so, it is necessary to develop reliable analytical methods for their therapeutic monitoring and quality control analysis. $\beta$-Lactam antibiotics are still known for their excellent safety and efficacy profile, they work by interfering with bacterial cell wall synthesis which is absent in human cell. ${ }^{50}$ From the literature survey discussed above, no HPTLC method was published for the simultaneous quantitation of different $\beta$-lactam antibiotics in real plasma samples. Thin layer chromatography is solid liquid chromatographic method at which the separation depends on the difference in solubility and adsorption of different compounds between two phases (mobile phase and stationary phase) at which they are to be portioned. The developed HPTLC method has advantages of short analysis time and low solvent consumption which are economically effective. In addition, solvents used have harmless environmental impact which is essential in the field of green chemistry.

\section{Method development and optimization}

The main goal during optimization of the developing system was to test green solvents and exclude harmful ones such as chloroform, methylene chloride, benzene, etc. Different mobile phase mixtures were tested starting with acetone : methanol $(9: 1,7: 3$, and $6: 3, \mathrm{v} / \mathrm{v})$ and ethylacetate : methanol $(9: 1$, $7: 3$, and $6: 3, \mathrm{v} / \mathrm{v})$. In both cases, no complete separation among the studied drugs and plasma was observed, moreover, spots of meropenem, cefepime, and plasma appeared near the baseline. However, ethylacetate was preferred than acetone as it gave compact spots and the ratio $(6: 3, \mathrm{v} / \mathrm{v})$ was chosen. Looking at the structure of the studied drugs, it was found that they contained both acidic and basic groups, hence their chromatographic resolution was expected to be $\mathrm{pH}$ dependent. Different ratios of ammonia solution (33\%), triethylamine, acetic acid, and formic acid were separately tested $(0.5,1$, and $1.5 \%)$. Adjusting the medium basic with either ammonia solution or triethylamine resulted in unresolved spots between 
cefotaxime and cefaclor. In one hand, changing the medium with acetic acid, meropenem and cefepime co-eluted with nearly the same $R_{\mathrm{f}}$ values. On the other hand, using formic acid (1\%) resulted in a reasonable separation between all spots. Water in different ratios was then added $(5,10$, and $15 \%)$ in a trial to improve separation between spots of plasma and cefepime. It was noticed that addition of $15 \%$ water improved the shape of all the separated spots and produced the best separation.

The use of internal standard during bio-analytical method development is important to correct for the variability in the analyte loss during sample treatment. Different internal standards were tested and the best one regarding the chromatographic behaviors and separation was valacyclovir. Sensitivity is
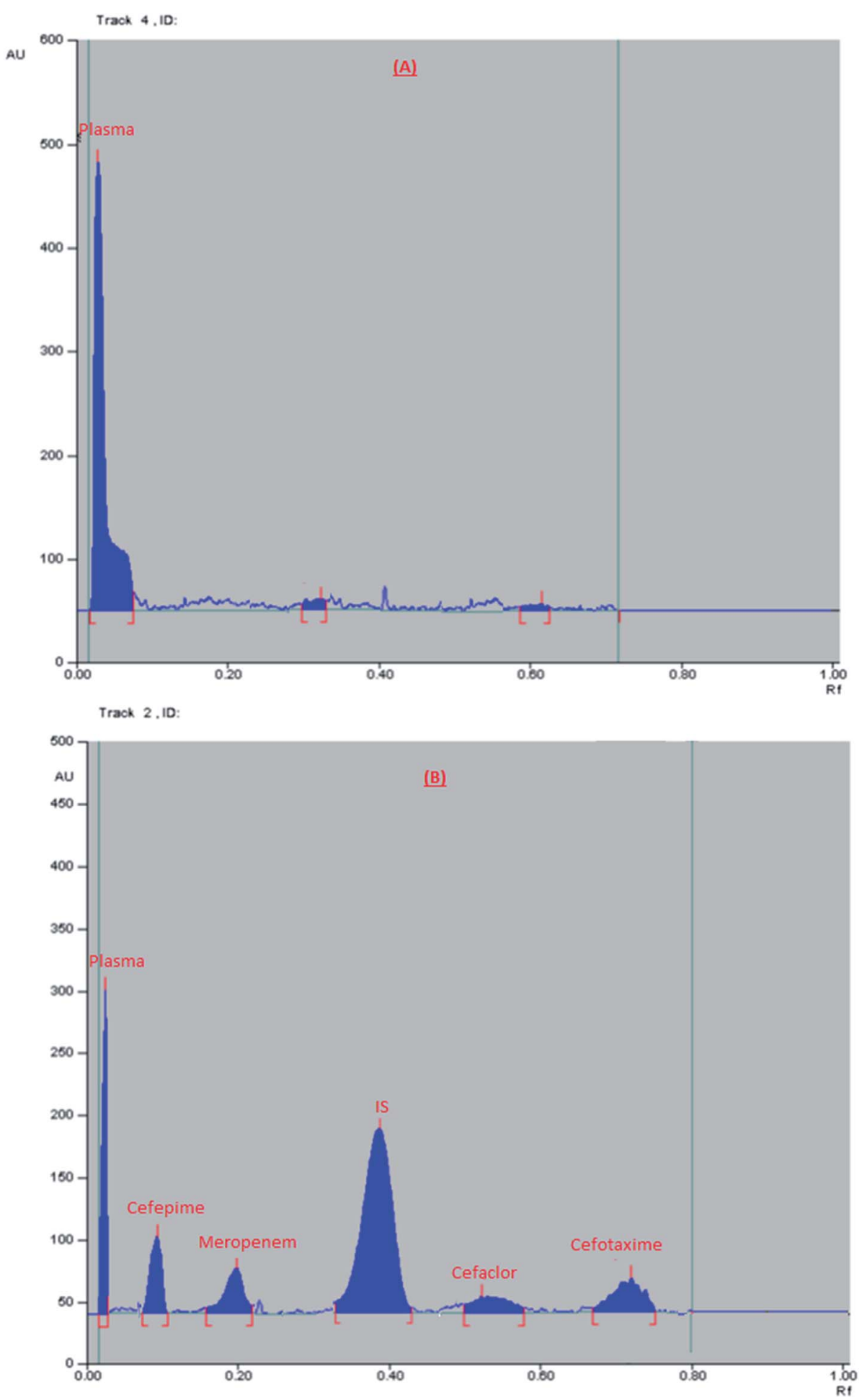

Fig. 1 2D chromatogram of (A) blank plasma, (B) plasma sample spiked with a mixture of the studied drugs (at their LLOQ) and internal standard. 
Table 1 Assay and method validation parameters for the determination of the studied drugs by the proposed method ${ }^{a}$

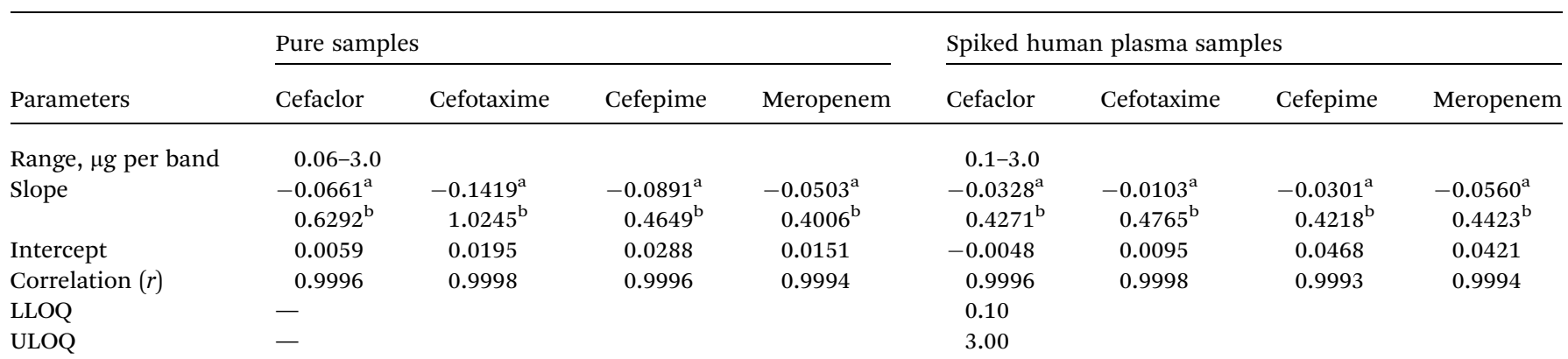

${ }^{a}$ The linearity was achieved using the polynomial regression equation: $A=a X^{2}+b X+C .{ }^{\mathrm{a}}$ : coefficient $1 .^{\mathrm{b}}$ : coefficient $2 . A=$ peak area ratio (peak area of the analyte/peak area of IS), $X=$ concentration $\mu \mathrm{g}$ per band. $C=$ intercept.

an important factor for methods applied to biological fluids, different scanning wavelengths $(230,254,270$, and $290 \mathrm{~nm})$ were tested and the highest sensitivity was obtained on scanning at $270 \mathrm{~nm}$ for all the proposed $\beta$-lactam antibiotics. In the same way, time of equilibration required before development is important to attain homogeneity of the atmosphere, thus diminishes the evaporation of the solvent from the HPTLC plate during the development. Effect of mobile phase saturation time on the chromatographic separation was tested (15 and $30 \mathrm{~min}$.), where no considerable effect was revealed.
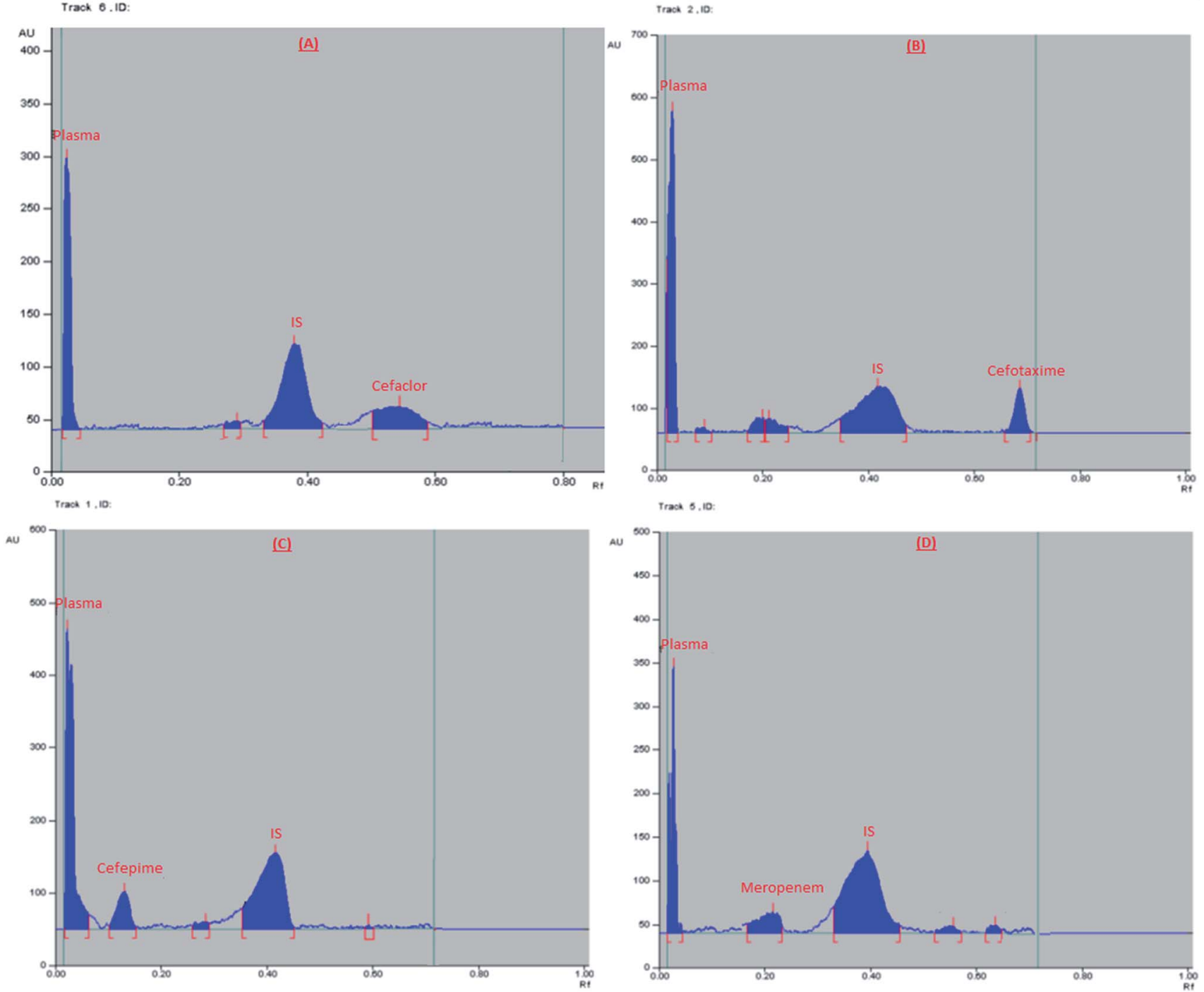

Fig. 2 2D chromatogram of real plasma samples obtained from healthy volunteers at their $t_{\max }$. 
Finally, the optimum conditions were; mobile phase mixture of ethyl acetate : methanol : water : formic acid $(6: 3: 1.5: 0.1$, by volume), the saturation time was $15 \mathrm{~min}$., and UV scanning at $270 \mathrm{~nm}$. The obtained $R_{\mathrm{f}}$ values were: $0.04,0.1,0.19,0.38$, 0.55 , and 0.76 for plasma, cefepime, meropenem, IS, cefaclor, and cefotaxime, respectively, Fig. 1.

After optimization of the method, linearity was first checked by construction of calibration curves using pure standards of the studied antibiotics. Calibration curves relating the peak area ratio (area of the pure standard/area of IS) to the corresponding concentrations were plotted and linearity was proven using polynomial regression in the concentration ranges of 0.06-3 $\mu \mathrm{g}$ per band for all the proposed drugs. The computed regression equations are given in Table 1.

\section{Method validation}

Validation of the proposed analytical method was carried out following $\mathrm{FDA}^{45}$ guidelines for bio-analytical method validation.

Linearity of calibration curves, lower limits of quantification, and quality control samples. Calibration range of plasma samples spiked with the studied drugs was established in the concentration range of $0.1-3 \mu \mathrm{g}$ per band for all the proposed antibiotics using peak area ratio and polynomial regression, Table 1. Moreover, lower limit of quantitation (LLOQ) was tested and considered to be the lowest concentration on the calibration curve that have a precision with $\%$ RSD $\leq 20 \%$ and its accuracy should be within $100 \pm 20 \%$ of the actual concentration. LLOQ was found to be $0.1 \mu \mathrm{g}$ per band for cefaclor, cefotaxime, cefepime, and meropenem. Additionally, upper limit of quantitation (ULOQ) was tested to be the highest concentration on the plotted calibration curve with precision of $\%$ RSD $\leq 15 \%$ and accuracy within $100 \pm 15 \%$. ULOQ was calculated and found to be $3 \mu \mathrm{g} \mathrm{mL}^{-1}$ for the studied four components.
Quality control samples (QCs). Three QC samples were chosen, the first one (low QC (LQC)) should be at least three times as LLOQ, the second sample was (middle QC (MQC)), which should be within the middle of the calibration curve, and the third sample was chosen to be at the high end of the calibration graph and lower than ULOQ and it was called (high QC (HQC)). The selected QC samples were 0.6, 1.5, and $2.5 \mu \mathrm{g}$ per band for all the studied $\beta$-lactam antibiotics.

Concentrations of the samples of calibration standard and QC samples were calculated using the computed regression equations given in Table 1 . The results of each sample (calibration standards and quality control samples) were accepted when deviation is not more than $15 \%$ from the true concentrations $(100 \pm 15 \%)$ while that of LLOQ was accepted when its deviation was $\leq 20 \%(100 \pm 20 \%)$ from the nominal concentration.

Specificity and selectivity. Specificity of the method is the ability of the method to differentiate between the analyte of interest and the endogenous plasma components. It was tested by comparing HPTLC chromatograms obtained from applying blank plasma samples (from six different plasma batches), plasma samples spiked with each of the studied four drugs at their LLOQ and IS, and plasma samples obtained from healthy volunteers received the specified dose of each drug. HPTLC chromatograms in Fig. 1 and 2 proved that there was no interference among the studied components and plasma matrix, and confirmed selectivity of the method.

Accuracy and precision. Four samples (LLOQ and QC samples) were used to evaluate accuracy and precision of the developed HPTLC method. Within run accuracy and precision was tested by analysis of the four samples $(n=3)$ in the same day while between run precision and accuracy was checked by analysis of the prepared samples $(n=3)$ on three successive days. The resulted concentrations were calculated from the previously computed regression equations. Accuracy was

Table 2 Intra and inter assay precision and accuracy

\begin{tabular}{|c|c|c|c|c|c|c|c|}
\hline \multirow[b]{2}{*}{ Component } & \multirow[b]{2}{*}{ Concentration $^{a}$ ( $\mu \mathrm{g}$ per band) } & \multicolumn{3}{|l|}{ Intraday } & \multicolumn{3}{|l|}{ Interday } \\
\hline & & Recovery\% & RSD\% & Bias $\% ~^{b}$ & Recovery\% & RSD\% & Bias $\%{ }^{b}$ \\
\hline \multirow[t]{4}{*}{ Cefaclor } & 0.10 (LLOQ) & 102.56 & 7.29 & 2.56 & 91.98 & 8.13 & -8.02 \\
\hline & $0.60(\mathrm{LQC})$ & 108.02 & 2.83 & 8.02 & 99.79 & 8.60 & -0.21 \\
\hline & 1.50 (MQC) & 99.57 & 0.04 & -0.43 & 109.34 & 9.40 & 9.34 \\
\hline & $2.50(\mathrm{HQC})$ & 104.64 & 7.49 & 4.64 & 104.86 & 9.72 & 4.86 \\
\hline \multirow[t]{4}{*}{ Cefotaxime } & 0.10 (LLOQ) & 105.5 & 8.47 & 5.75 & 93.07 & 9.63 & -6.93 \\
\hline & 0.60 (LQC) & 93.97 & 5.09 & -6.03 & 107.56 & 13.42 & 7.56 \\
\hline & $1.50(\mathrm{MQC})$ & 94.32 & 7.92 & -5.68 & 91.48 & 10.09 & -8.52 \\
\hline & $2.50(\mathrm{HQC})$ & 99.13 & 6.76 & -0.87 & 89.66 & 7.47 & -10.30 \\
\hline \multirow[t]{4}{*}{ Cefepime } & 0.10 (LLOQ) & 116.77 & 3.91 & 16.77 & 118.46 & 1.84 & 18.46 \\
\hline & $0.60(\mathrm{LQC})$ & 105.52 & 4.42 & 5.52 & 103.65 & 6.24 & 3.65 \\
\hline & 1.50 (MQC) & 106.34 & 5.77 & 6.34 & 108.67 & 9.55 & 3.65 \\
\hline & 2.50 (HQC) & 96.21 & 6.53 & -3.79 & 95.29 & 9.15 & -4.71 \\
\hline \multirow[t]{4}{*}{ Meropenem } & 0.10 (LLOQ) & 102.56 & 4.57 & 2.56 & 107.22 & 10.53 & 7.22 \\
\hline & 0.60 (LQC) & 98.74 & 6.19 & -1.26 & 109.01 & 3.31 & 8.99 \\
\hline & 1.50 (MQC) & 90.00 & 4.20 & -10.00 & 97.67 & 9.17 & -2.33 \\
\hline & 2.50 (HQC) & 106.35 & 0.31 & 6.35 & 99.21 & 8.84 & -0.79 \\
\hline
\end{tabular}

${ }^{a}$ Average of 3 experiments. ${ }^{b}$ Bias $=[($ measured concentration - nominal concentration $) /$ nominal concentration $] \times 100$. 
Table 3 Extraction recovery results of the studied drugs in spiked human plasma

\begin{tabular}{lll}
\hline Analyte & $\begin{array}{l}\text { Concentration of } \\
\text { the analyte }(\mu \mathrm{g} \text { per band })\end{array}$ & \% recovery ${ }^{a}$ \\
\hline Cefaclor & 0.60 & 88.56 \\
& 1.50 & 93.25 \\
& 2.50 & 95.57 \\
Mean \pm \% RD & & $92.46 \pm 3.862$ \\
Cefotaxime & 0.60 & 76.86 \\
& 1.50 & 73.19 \\
Mean \pm \% RSD & 2.50 & 80.80 \\
& & $76.75 \pm 4.946$ \\
Cefepime & 0.60 & 91.24 \\
& 1.50 & 86.96 \\
Mean \pm \% RSD & 2.50 & 96.94 \\
& & $91.71 \pm 5.459$ \\
Meropenem & 0.60 & 94.95 \\
& 1.50 & 95.68 \\
Mean \pm \% RSD & 2.50 & 97.41 \\
IS & & $90.01 \pm 1.316$ \\
A & & \\
& & \\
& &
\end{tabular}

expressed as the bias [[(calculated concentration - actual concentration)/actual concentration] $\times 100]$, while precision was expressed as the coefficient of variation $(\mathrm{CV})$ or \% RSD [(SD/ mean) $\times 100]$. Results in Table 2 were within the acceptance limits (bias was within $\pm 15 \%$ for QC samples and $\pm 20 \%$ for LLOQ while CV was $\leq 15 \%$ for QC samples and $\leq 20 \%$ for LLOQ).
Extraction recovery. Extraction recovery was calculated for both the studied analytes and IS and it was evaluated by comparing the peak areas for the extracted QC samples with those of un-extracted standards (represent 100\% recovery). Results should be reproducible to be acceptable, regardless the resulting extraction recovery. The mean extraction recoveries were calculated and found to be $92.46 \pm 3.862$, 76.75 \pm 4.946 , $91.71 \pm 5.459$, and $90.01 \pm 1.316$ for cefaclor, cefotaxime, cefepime, and meropenem, respectively. The results given in Table 3 confirmed the efficiency of the extraction procedure followed in this work.

Stability of quality control samples. The stability was tested by exposing QC samples to variable stability conditions such as bench-top stability and freeze-thaw stability. QC samples were stored at room temperature $\left(25^{\circ} \mathrm{C}\right)$ for $6 \mathrm{~h}$ to test bench-top stability and also were subjected to three freeze-thaw cycles (from freezing at $-20{ }^{\circ} \mathrm{C}$ for $12 \mathrm{~h}$ to room temperature (freeze and thaw stability)). Sample was considered stable when the change in the analyte concentration was $\leq 15 \%$. Results presented in Table 4 assured that samples concentrations did not significantly changed under the tested stability conditions.

\section{Results of method application to real human plasma samples}

The developed HPTLC method was successfully used to determine the concentration of a single dose of the studied antibiotics in real human plasma of healthy volunteers. From previous studies, it was reported that $C_{\max }\left(\mu \mathrm{g} \mathrm{mL}^{-1}\right)$ for the given doses was $18.16,102,78.7$, and $70 \mu \mathrm{g} \mathrm{mL}{ }^{-1}$ for cefaclor, cefotaxime, cefepime, and meropenem, respectively. ${ }^{46-49}$ Chromatograms obtained from selected plasma samples are shown in Fig. 2. Additionally, the concentrations of the given doses were calculated from the previously computed regression

Table 4 Stability results of the studied drugs in spiked human plasma at different conditions

\begin{tabular}{|c|c|c|c|}
\hline \multirow[b]{2}{*}{ Analyte } & \multicolumn{3}{|l|}{$\%$ recovery $^{a}$} \\
\hline & $\begin{array}{l}\text { Concentration of the } \\
\text { analyte ( } \mu \text { g per band) }\end{array}$ & $\begin{array}{l}\text { Three freeze-thaw } \\
\text { cycles }\end{array}$ & Bench top stability \\
\hline \multirow[t]{3}{*}{ Cefaclor } & 0.60 & 103.79 & 96.72 \\
\hline & 1.50 & 99.30 & 111.39 \\
\hline & 2.50 & 89.90 & 109.67 \\
\hline Mean $\pm \%$ RSD & & $97.66 \pm 7.256$ & $105.93 \pm 7.57$ \\
\hline \multirow[t]{3}{*}{ Cefotaxime } & 0.60 & 106.89 & 99.63 \\
\hline & 1.50 & 97.54 & 107.50 \\
\hline & 2.50 & 98.78 & 96.8 \\
\hline Mean $\pm \%$ RSD & & $101.07 \pm 5.024$ & $101.31 \pm 5.473$ \\
\hline \multirow[t]{3}{*}{ Cefepime } & 0.60 & 108.37 & 89.87 \\
\hline & 1.50 & 107.18 & 92.37 \\
\hline & 2.50 & 110.63 & 89.78 \\
\hline Mean $\pm \%$ RSD & & $108.73 \pm 1.612$ & $90.67 \pm 1.621$ \\
\hline \multirow[t]{3}{*}{ Meropenem } & 0.60 & 99.08 & 110.13 \\
\hline & 1.50 & 96.24 & 111.33 \\
\hline & 2.50 & 104.79 & 100.00 \\
\hline Mean $\pm \%$ RSD & & $100.04 \pm 4.353$ & $107.15 \pm 5.808$ \\
\hline
\end{tabular}

${ }^{a}$ Average of 3 determinations. 
Table 5 Results of determination of the studied drugs in real human plasma

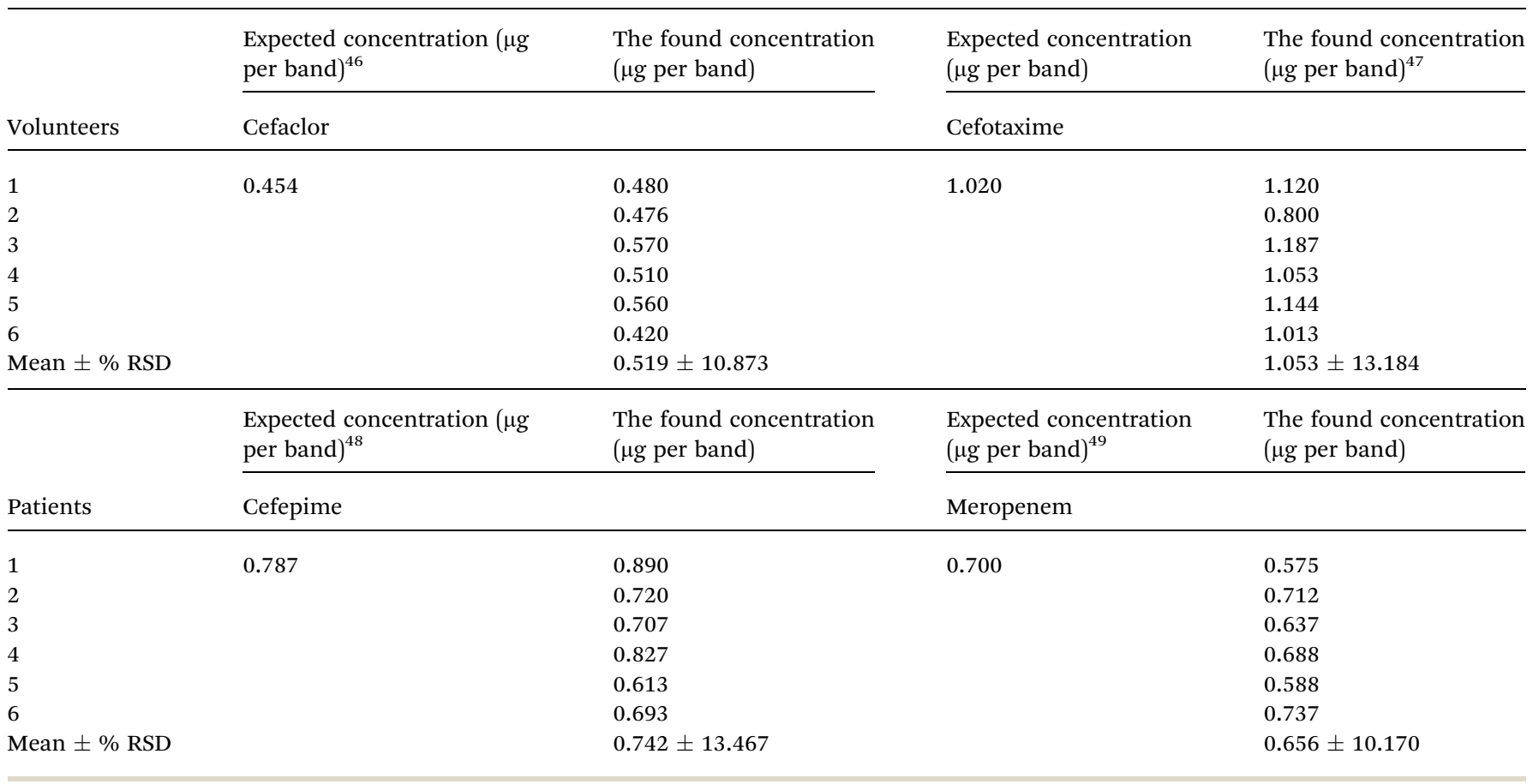

equations and summarized in Table 5. All the plasma concentrations measured in volunteers samples were within the calibration range of the proposed HPTLC method.

\section{Conclusion}

An innovative HPTLC method was established for in vivo analysis of four $\beta$-lactam antibiotics. The method had the advantages of simple sample preparation and short analysis time. Moreover, the proposed method adopted the use of green solvents with harmless environmental impact. All validation parameters agreed with FDA acceptance criteria. This method permitted the accurate determination of the studied antibiotics thus, it can be used during therapeutic drug monitoring in daily clinical practice, hence minimize the antibiotics microbial resistance.

\section{Ethics}

The study was approved by the Animal Care and Use Committee of the Faculty of Medicine, Beni-Suef University (FM-BSU REC) according to guidelines of the declaration of Helsinki, International Conference on Harmonization (ICH) and United States Codes of Federal Regulation and registered in under the Federal Wide Assurance number (REC-A-PHBSU18005) for protection of animals (appendix 1).

\section{Conflicts of interest}

Both authors declare that they have no conflicts of interest.

\section{Acknowledgements}

All authors wish to thank the staff of Dr Khaled Nagy Laboratory, Beni-Suef, Egypt for their efforts in collecting the blank plasma samples.

\section{References}

1 R. P. Elander, Industrial production of $\beta$-lactam antibiotics, Appl. Microbiol. Biotechnol., 2003, 61, 385-392.

2 J. A. Torres, M. V. Pillegas and J. P. Quinn, Current concepts in antibiotic resistant gram negative bacteria, Expert Rev. Anti-Infect. Ther., 2007, 5, 833-843.

3 A. M. Queenan and K. Bush, Carbapenemases: the versatile B-lactamases, Clin. Microbiol. Rev., 2007, 20, 440-485.

4 L. P. Consortti and H. R. N. Salgado, A critical review of analytical methods for quantification of cefotaxime, Crit. Rev. Anal. Chem., 2017, 47, 359-371.

5 M. A. Omkulthom, Review on determination of cefepime in biological fluids by different analytical methods, $J$. Innovations Pharm. Biol. Sci., 2016, 3, 141-146.

6 V. Granados-Soto, M. E. Aguilar-Cota, G. Reyes-Garcia, R. Medina-Santillán and F. J. Flores-Murrieta, Simple method for the determination of cefaclor in human plasma samples by HPLC, J. Liq. Chromatogr. Relat. Technol., 2003, 26, 3315-3323.

7 B. J. Z. Ruan, H. Lou, D. Xu and H. Yuan, Determination of cefaclor in human plasma by reversed-phase highperformance liquid chromatography with UV detection and its application to the bioequivalence studies, Anal. Lett., 2009, 42, 210-2179. 
8 S. Naz, M. H. Shoaib, L. Bashir, R. I. Yousuf, F. Anjum, F. Siddiqui and S. Yaseen, HPLC method development and validation for the determination of cefaclor in human plasma, Pak. J. Pharm. Sci., 2017, 30, 1645-1649.

9 S. E. Briscoe, B. C. McWhinney, J. Lipman, J. A. Roberts and J. P. J. Ungerer, A method for determining the free (unbound) concentration of ten betalactam antibiotics in human plasma using high performance liquid chromatography with ultraviolet detection, J. Chromatogr. B: Anal. Technol. Biomed. Life Sci., 2012, 907, 178-184.

10 T. Legrand, D. Vodovar, N. Tournier, N. Khoudour and A. Hulina, Simultaneous determination of eight $\beta$-Lactam antibiotics, amoxicillin, cefazolin, cefepime, cefotaxime, ceftazidime, cloxacillin, oxacillin, and piperacillin, in human plasma by using ultra-high- performance liquid chromatography with ultraviolet detection, Antimicrob. Agents Chemother., 2016, 60, 4734-4742.

11 T. Legrand, S. Chhun, E. Rey, B. Blanchet, J. Zahar, F. Lanternierd, G. Ponsa and V. Jullien, Simultaneous determination of three carbapenem antibiotics in plasma by HPLC with ultraviolet detection, J. Chromatogr. B: Anal. Technol. Biomed. Life Sci., 2008, 875, 551-556.

12 B. C. McWhinney, S. C. Wallis, T. Hillister, J. a. Roberts, J. Lipman and J. P. J. Ungerer, Analysis of 12 beta-lactam antibiotics in human plasma by HPLC with ultraviolet detection, J. Chromatogr. B: Anal. Technol. Biomed. Life Sci., 2010, 878, 2039-2043.

13 K. Kipper, K. Anier, I. Leito, J. Karjagin, K. Oselin and K. Herodes, Rapid determination of meropenem in biological fluids by LC: comparison of various methods for sample preparation and investigation of meropenem stability, Chromatographia, 2009, 70, 1423-1427.

14 T. Roth, S. Fiedler, S. Mihai and H. Parsch, Determination of meropenem levels in human serum by high-performance liquid chromatography with ultraviolet detection, Biomed. Chromatogr., 2017, 31, 1-7.

15 E. Dailly, R. Bouquié, G. Deslandes, P. Jolliet and R. Le Floch, A liquid chromatography assay for a quantification of doripenem, ertapenem, imipenem, meropenem concentrations in human plasma: application to a clinical pharmacokinetic study, J. Chromatogr. B: Anal. Technol. Biomed. Life Sci., 2011, 879, 1137-1142.

16 X. Chen, D. Zhong, B. Huang and J. Cui, Determination of cefaclor in human plasma by a sensitive and specific liquid chromatographic-tandem mass spectrometric method, J. Chromatogr. B: Anal. Technol. Biomed. Life Sci., 2003, 784, 17-24.

17 C. H. W. Wang and L. Miao, Determination of cefaclor by UPLC-MS-MS for a Chinese pharmacokinetic study, $J$. Chromatogr. Sci., 2014, 52, 636-640.

18 M. Carlier, V. Stove, J. A. Roberts, E. Van de Velde, J. J. De Waele and A. G. Verstraete, Quantification of seven $\beta$ lactam antibiotics and two $\beta$-lactamase inhibitors in human plasma using a validated UPLC-MS/MS method, Int. J. Antimicrob. Agents, 2012, 40, 416-422.

19 F. B. Sime, M. S. Roberts, J. A. Roberts and T. A. Robertson, Simultaneous determination of seven $\beta$-lactam antibiotics in human plasma for therapeutic drug monitoring and pharmacokinetic studies, J. Chromatogr. B: Anal. Technol. Biomed. Life Sci., 2014, 960, 134-144.

20 R. Cazorla-Reyes, R. Romero-Gonzalez, A. Garrido Frenich, M. A. R. Maresca and J. L. M. Vidal, Simultaneous analysis of antibiotics in biological samples by ultra high performance liquid chromatography-tandem mass spectrometry, J. Pharm. Biomed. Anal., 2014, 89, 203-212.

21 P. Colin, L. De Bock, H. T'Jollyn, K. Boussery and J. Van Bocxlaer, Development and validation of a fast and uniform approach to quantify beta-lactam antibiotics in human plasma by solid phase extraction-liquid chromatography-electrospray-tandem mass spectrometry, Talanta, 2013, 103, 285-293.

22 T. Ohmori, A. Suzuki, T. Niwa, H. Ushikoshi, K. Shirai, S. Yoshida, et al., Simultaneous determination of eight $\beta$ lactam antibiotics in human serum by liquid chromatography-tandem mass spectrometry, J. Chromatogr. B: Anal. Technol. Biomed. Life Sci., 2011, 879, 1038-1042.

23 M. Carlier, V. Stove, J. J. de Waele and A. G. Verstraete, Ultrafast quantification of $\beta$-lactams antibiotics in human plasma using UPLC-MS/MS, J. Chromatogr. B: Anal. Technol. Biomed. Life Sci., 2015, 978-979, 89-94.

24 M. Kummer, N. Šestáková, R. Theurillat, U. Huynh-Do, A. Endimiani, P. Sendi and W. Thormann, Monitoring of cefepime in urine by micellar electrokinetic capillary chromatography with UV detection and liquid chromatography coupled to mass spectrometry, J. Sep. Sci., 2018, 41, 4067-4074.

25 R. Theurillat, J. Joneli, U. Wanzenried, J. Schiess, M. Hurni, T. Weber, P. Sendi and W. Thormann, Therapeutic drug monitoring of cefepime with micellar electrokinetic capillary chromatography: assay improvement, quality assurance, and impact on patient drug levels, J. Sep. Sci., 2016, 39, 2626-2632.

26 N. Šestáková, R. Theurillat, P. Sendi and W. Thormann, Monitoring of cefepime in human serum and plasma by micellar electrokinetic capillary chromatography. Improvement of sample preparation and validation by liquid chromatography coupled to mass spectrometry, $J$. Sep. Sci., 2017, 40, 1805-1814.

27 A. Al-Attas, J. J. Nasr, N. El-Enany and F. Belal, A green capillary zone electrophoresis method for the simultaneous determination of piperacillin, tazobactam and cefepime in pharmaceutical formulations and human plasma, Biomed. Chromatogr., 2015, 29, 1811-1818.

28 T. Kitahashi and I. Furuta, Determination of meropenem by capillary electrophoresis using direct injection of serum, $J$. Chromatogr. Sci., 2005, 43, 430-433.

29 D. Agbaba, S. Eric, D. Zivanov Stakic and S. Vladimirov, HPTLC assay of cephalexin and cefaclor in pharmaceuticals, Biomed. Chromatogr., 1998, 12, 133-135.

30 S. Eric-Jovanovic, D. Agbaba, D. Zivanov-Stakic and S. Vladimirov, HPTLC determination of ceftriaxone, cefixime and cefotaxime in dosage forms, J. Pharm. Biomed. Anal., 1998, 18, 893-898. 
31 R. K. Nanda, S. E. Bhagwat, S. E. Potawale and S. C. Hamane, Development and validation of HPTLC method for simultaneous densitometric analysis of cefotaxime sodium and sulbactam sodium as the bulk drugs and in the pharmaceutical dosage form, J. Pharm. Res., 2010, 3, 16671669.

32 M. Dąbrowska, M. Starek and S. Pikulska, Simultaneous identification and quantitative analysis of eight cephalosporins in pharmaceutical formulations by TLCdensitometry, J. Planar Chromatogr.-Mod. TLC, 2011, 24, 23-29.

33 M. Dąbrowska, M. Starek, J. Krzek, E. Papp and P. Król, A degradation study of cefepime hydrochloride in solutions under various stress conditions by TLC-densitometry, Biomed. Chromatogr., 2015, 29, 388-395.

34 N. A. Elragehy, E. M. Abdel-Moety, N. Y. Hassan and M. R. Rezk, Stability-indicating determination of meropenem in presence of its degradation product, Talanta, 2008, 77, 28-36.

35 M. Dabrowska, W. Opoka and M. Starek, Determination of cefuroxime axetil and cefepime in biological materials by thin-layer chromatography-densitometry, J. Planar Chromatogr.-Mod. TLC, 2017, 30, 291-298.

36 M. Tomczyka, A. Bazylkob and J. Bonarewicz, Method development and validation for optimized separation of quercetin derivatives in selected Potentilla species using high-performance thin-layer chromatography photodensitometry method, J. Pharm. Biomed. Anal., 2012, 61, 265-270.

37 B. Renger, Z. Végh and K. Ferenczi-Fodor, Validation of thin layer and high performance thin layer chromatographic methods, J. Chromatogr. A, 2011, 1218, 2712-2721.

38 N. S. Abdelwahab, Determination of atenolol, chlorthalidone and their degradation products by TLC-densitometric and chemometric methods with application of model updating, Anal. Methods, 2010, 2, 1994-2001.

39 N. F. Farid and N. S. Abdelwahab, Stability-indicating HPTLC method for studying stress degradation behavior of sulbutiamine HCl, J. Chromatogr. Sci., 2016, 4, 609-617.

40 E. A. Abdelaleem and N. S. Abdelwahab, Green chromatographic method for analysis of some anti-cough drugs and their toxic impurities with comparison to conventional methods, Saudi Pharm. J., 2018, 26, 1185-1191. 41 N. S. Abdelwahab, N. F. Fared, M. Elagawany and E. H. Abdelmomen, Different spectrophotometric and chromatographic methods for determination of mepivacaine and its toxic impurity, J. AOAC Int., 2017, 100, 1392-1399.

42 N. S. Abdelwahab, H. A. H. Elshemy and N. F. Farid, determination of flutamide and two major metabolites using HPLC-DAD and HPTLC methods, Chem. Cent. J., 2018, 12, 1-15.

43 M. Y. Fares, N. S. Abdelwahab, M. M. Abdelrahman and H. M. Abdel-Rahman, Determination of sofosbuvir with two co-administered drugs; paracetamol and DLmethionine by two chromatographic methods, Bioanalysis, 2019, 11(5), 349-364.

44 T. Rojanarata, Green pharmaceutical chemistry for the sustainability, Silpakorn Univ. Sci. Technol. J., 2012, 6(1), 713.

45 FDA, Guidance for Industry Bio-analytical Method Validation, 2013.

46 M. Tutunji, O. Jarrar, M. Musameh, S. M. Alam, Quamruzaman and R. Dham, Bioequivalence evaluation of two brands of cefaclor $500 \mathrm{mg}$ capsules: quantification of cefaclor using solid phase extraction technique, J. Clin. Pharm. Ther., 2001, 26, 149-153.

47 Through web site: https:/webcache.googleusercontent.com/ search?q=cache:9Avp6yAV6mUJ: https:// www.medsafe.govt.nz/profs/Datasheet/c/

Cefotaximeinjaft.pdf $+\& \mathrm{~cd}=8 \& \mathrm{hl}=\mathrm{en} \& \mathrm{ct}=\mathrm{clnk} \& \mathrm{gl}=\mathrm{eg}$, accessed February 2019, 10.0 PM.

48 Through web site: https:/www.accessdata.fda.gov/ drugsatfda_docs/label/2012/050679s036lbl.pdf, accessed February 2019, 10.0 PM.

49 H. C. Kelly, M. Hutchison and S. J. Haworth, A comparison of the pharmacokinetics of meropenem after administration by intravenous injection over $5 \mathrm{~min}$ and intravenous infusion over $30 \mathrm{~min}$, J. Antimicrob. Chemother., 1995, 36, 35-41.

50 Through website: https://pharmafactz.com-medicinalchemistry-of-beta-lactam-antibiotics, accessed March 2019, 6.00 PM. 